\title{
The Prevention and Treatment of Rabbits Poisoning Synthetic Pyretroid Esphenvaleriate
}

\author{
Salimova Iroda Yunusovna* \\ Samarkand Institute of Veterinary Medicine, Uzbekistan
}

*Corresponding author: Salimova Iroda Yunusovna, Samarkand Institute of Veterinary Medicine, Uzbekistan

\begin{abstract}
The aryicle presents identified causes, clinical symptoms and pathological anatomy of poisons, also developed by effective measures diagnosis, prevention and treatment of poison rabbits with pyretroid esphenvaleriat.
\end{abstract}

Keywords: Pesticides; Insecticides; Piretroides; Cypervet; Sumina; Esphenvaleriat; Superkiller; Deltanur-1; Mdu

\section{Introduction}

In recent years, chemical preparations are widely used to protect plants and animals from various pests and diseases (pesticides) from a group of synthetic pyrethroids. Among modern insecticides permitted for use in agriculture and veterinary medicine, synthetic pyrethroids account for 75-80\% [1]. Pesticides in this group have a high selective effect on pests, a relatively low risk to warm-blooded animals, the rapid biodegradation of many of the objects in the external environment. Currently in crop production and veterinary practice of Uzbekistan the most widely used synthetic pyrethroids such as sipernet, suminat, esfenvalerate, killer, deltaur-1, etc.

\section{Purpose and Objectives of the Study}

Safety of widespread use pyrethroid drug esphenvaleriata in various sectors of agriculture in Uzbekistan, requires the development of effective measures of diagnosis, prevention and treatment of possible poisoning of farm animals [2].

\section{Material and Methods}

The Study was conducted on rabbits with the use of pyrethroid drug esfenvalerate. For determination of pyrethroid in pathological material and veterinary objects supervision used techniques developed by MA Klisenko [3] and others, and also "Temporary methodical instructions on determination of SP by method of gasliquid chromatography in milk and meat of animals" (addition to № 2473-81 of 22.10.81). One hundred seventy nine [4].

\section{Results}

The cause of poisoning of animals in production conditions is the ingress of pyrethroid in feed and water sources, as a result of gross violations of the requirements of the instructions for storage, transportation and use of esphenvaleriate, overstatement and multiplicity of application, [5] as a result of adverse weather conditions, non-compliance with the waiting period after the treatment of forage and food crops, as well as non-compliance with the regulations for the use of pyrethroid for veterinary purposes [6].

\section{Clinical Symptoms}

Acute toxicity to rabbits of the synthetic pyrethroidesfenvalerate mainly characterized by dysfunction of Central and autonomic nervous system. They are manifested by General oppression, loss of appetite, salivation, tremor, bronchospasm, peristalsis of the gastrointestinal tract, paresis, violation of coordination of movements, convulsions, paralysis of limbs, comatose state. Death rabbits comes in the first 24-72 hours, after embody in their organism esfenvaleriat in doses, close to LD50 $(360 \mathrm{mg} / \mathrm{kg})$. The time of manifestation and severity of clinical symptoms of poisoning, the severity of the intoxication process, the outcome and timing of recovery, depend on the dose of the toxicant. For esfenvalerate characterized by a high curare-like action. In the blood of rabbits poisoned by esfenvalerate reduced the level of 
hemoglobin of $12 \%$, the number of formed elements is $13 \%$, the osmotic resistance of erythrocytes in, $20 \%$, content of total and reduced glutathione by $6-10 \%$ and the activity acetylcholinesterase by $26 \%$. At the same time increasing the content of methemoglobin 3 times and the activity of serum transminases (ASAT and Alat) by 2.6 times.

Immunological parameters are characterized by a decrease in the relative and absolute number of T-cells by $30-58 \%$, neutrophil phagocytic activity by $36 \%$ in the nst test, with an increase in the relative and absolute number of b-lymphocytes by 1.5-1.6 times. The main pathoanatomical changes in rabbits of the fallen as a result of acute poisoning with esphenvaleriates, there are acute hemodynamic disorders in the brain and internal organs with the phenomena of acute catarrhal inflammation of the gastric mucosa and the small intestine. Consequently, in the pathogenesis of intoxication of rabbits esfenvalerate have place him high kurarepodobnami, methemoglobin formation, hepatotoxicity, anticholinesterase, membranoids and immunosuppressive effects, indicating polytropic mechanism of toxic action. The drug can also have a negative effect on reproductive function of rabbits.

Diagnosis of poisoning rabbits esfenvalerate should be comprehensive taking into account anamnestic data, information about the use of piretroids farms, contact with animals, the results of clinical studies, with the exception of poisoning FOS and carbamates such diseases,as rabies, a disease Awecki, tetanus, botulism. The importance of the differential diagnosis of poisoning esfenvalerate has the determination of activity of enzyme acetylcholinesterase in the peripheral blood. The activity of this enzyme in the blood of rabbits poisoned-180 cov esfenvalerate suppressed only by 26$30 \%$. In cases of poisoning by carbamates and organophosphorus poisons the activity of the enzyme is reduced by $60-80 \%$ or more. The highest levels of pyrethroids are usually found in the stomach, liver, kidney, lungs, myocardium and spleen of fallen animals.

\section{Treatment}

Polytropic mechanism of toxic action of esfenvalerate greatly complicates the search for reliable antidotes for treatment poisoning them rabbits. Currently, there are no specific means for the effective treatment of such pathological conditions. According to this, the treatment poisoning of animals with synthetic pyrethroids is carried out mainly by means of pathogenetic therapy. Thus, a positive treatment effect in rabbits in acute poisoning esfenvalerate obtained from intramuscular injection of atropine sulfate $(0.5 \mathrm{mg} /$ $\mathrm{kg}$ ) and Mexidol (50mg/kg), ascorbic acid $(50 \mathrm{mg} / \mathrm{kg})$, gambit $(0,1 \mathrm{ml} / \mathrm{kg})$ and intravenous chromosome use $(0.5 \mathrm{mg} / \mathrm{kg})$. The frequency of administration of these drugs depends on the severity of intoxication and is from 3 to 5 times. The interval between injections of these means of correction 6-12 hours. The therapeutic effectiveness of their use, up to $70 \%$. However, in the late conduct of therapeutic measures therapeutic effectiveness is significantly reduced.

\section{Prevention}

Lack of reliable means of correction of poisoning animals (rabbits) modern synthetic pyrethroids significantly increases the role of measures aimed at preventing various negative effects of their aftereffect. Thus, successful prevention of poisoning and other adverse outcomes of exposure to synthetic PYRETHROID of esfenvalerate, along with compliance with regulations of storage, transportation and application in agriculture and veterinary practice, strict control over the content of residual quantities of the xenobiotic in the objects of veterinary supervision.

\section{Conclusion}

The Maximum residue level (MRL) of esfenvalerate in rabbit feed should not exceed $0.2 \mathrm{mg} / \mathrm{kg}$ of feed, respectively.

\section{References}

1. Makarov V (1976) Veterinary and sanitary examination of products of slaughter at toxic substances poisoning. In: Kolos M (Eds.), reference book on veterinary medicine toxicology of pesticides, Moscow, Russia, pp. 272c.

2. Homeland SD (1981) Protection of animals from ticks and insects. Moscow, Russia.

3. Klisenko MA (1984) Methods of determination of macro-quantities of pesticides. Medicine, Moscow, Russia.

4. Khaitov VR, Kubaev OS, Shakirov LH (1991) Temporary methodical instructions on the definition of aktellik in biological objects by gasliquid chromatography. Tashkent, Uzbekistan, p. 6s.

5. Galyautdinov GG, Abulkhanova GM, Tremasov MI, Zimakov GA (2005) Toxicological aspects of the use of synthetic pyrethroids in agriculture. Zh Veterinary 5: 51-56.

6. Yuldashev ZA, Popkov VA (2006) Chemical and Toxicological studies synthetic pyrethroids. University Press, Moscow, Russia 35: 152s. 


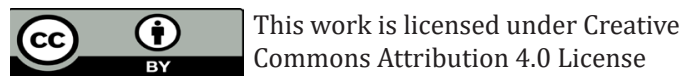

Submission Link: Submit Article

DOI: $10.32474 / C D V S .2019 .02 .000136$

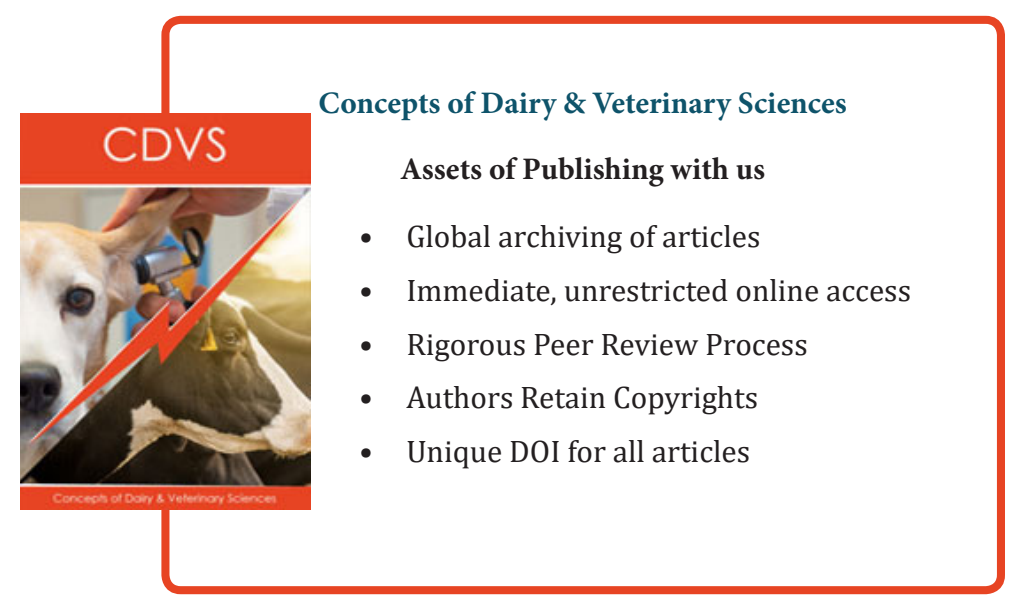

